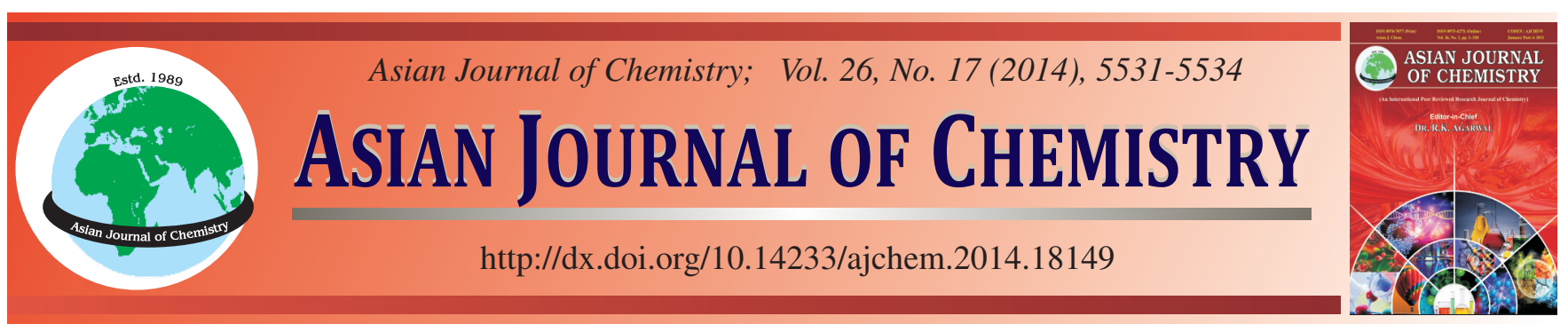

\title{
Adsorption of Methylene Blue on Sewage Sludge Based Granular Activated Carbon $\dagger$
}

\author{
L.H. LiU ${ }^{1}$, H.N. AI ${ }^{1}$, Y. LIN ${ }^{2}$, Y.Y. Liu' ${ }^{1}$ and Q. HE ${ }^{1, *}$
}

${ }^{1}$ Key Laboratory of Three Gorges Reservoir Region's Eco-environment, Ministry of Education, Chongqing University, Chongqing, P.R. China ${ }^{2}$ College of Resources and Environmental Science, Chongqing University, Chongqing, P.R. China

*Corresponding author: Tel./Fax: +86 23 65120980; E-mail: deanhenry_liu01@126.com; hq0980@126.com

In this study, sewage sludge based granular activated carbons used for adsorption of methylene blue were prepared using calcium sulphate as binder and activator. The effect of preparation conditions of activated carbons on methylene blue adsorption was investigated in detail. The optimized conditions were obtained with activation temperature $700{ }^{\circ} \mathrm{C}$, calcium sulphate and sludge mass ratio $30 \%$ and activation time $1 \mathrm{~h}$ as well as a heating rate of $5^{\circ} \mathrm{C} / \mathrm{min}$. The sample prepared for adsorption of methylene blue under the optimized conditions was $71.94 \mathrm{mg} / \mathrm{g}$. Nitrogen adsorption, scanning electron microscope (SEM) and Fourier transform infrared spectrum (FT-IR) were used to characterize the sample. The experimental results indicate that it is a typical mesoporous adsorbent. Many acidic groups and holes were found resulting from ablating on its surfaces. The activation mechanisms and reactions of calcium sulphate were similar to that of the combination of $\mathrm{H}_{2} \mathrm{SO}_{4}$ and $\mathrm{KOH}$.

Keywords: Granular activated carbon, Sewage sludge, Methylene blue adsorption, Calcium sulphate, Activation mechanism.

\section{INTRODUCTION}

Activated carbon (AC) is a highly effective adsorbent that is widely used for air and drinking water purification as well as industrial wastewater treatment ${ }^{1}$. Many materials rich in carbon can be used as precursors in the production of activated carbons such as oil sands coke ${ }^{2}$, coconut husk ${ }^{3}$ and cashew nut shell ${ }^{4}$. Taking into account that sewage sludge is carbonaceous in nature, it can be considered as potentially suitable raw material for the production of activated carbon ${ }^{5,6}$.

Many researchers have been paying lots of attentions to the preparation of powdered activated carbons from sewage sludge by chemical or physical activation method ${ }^{7,8}$ and the products have been investigated and used for the adsorption of pollutants in liquid, such as heavy metal ${ }^{9,10}$, dye $\mathrm{e}^{11,12}$, etc. However, there are few reports on the preparation of granular activated carbons from sewage sludge.

We have investigated the binders selected for preparing granular activated carbon from sewage sludge and found that calcium sulphate can not be only a binder, but also an activation agent. Hence, in this article, sewage sludge based granular activated carbons (SSGAC) for methylene blue adsorption was prepared from sewage sludge with calcium sulphate. The effects of activation temperature, activation time, heating rate and calcium sulphate dosages on the methylene blue adsorption were examined. The adsorption capacities of granular activated carbons for methylene blue were investigated and determined by the Langmuir equilibrium isotherms. Moreover, the activation mechanism of calcium sulphate was preliminarily discussed.

\section{EXPERIMENTAL}

Preparation of granular activated carbons: The raw material for the preparation of granular activated carbon was dewatered surplus sludges, which was obtained from Dadukou municipal wastewater treatment plant in Chongqing, P.R. China. Ultimate and proximate analysis results of the raw materials were shown in Table-1. The calcium sulphate $\left(\mathrm{CaSO}_{4} \cdot 2 \mathrm{H}_{2} \mathrm{O}, \mathrm{AR}\right)$ was used as-received (Kelong Co. Ltd., Chengdu, China).

The sludge sample was first dried at $105^{\circ} \mathrm{C}$ for $24 \mathrm{~h}$ and then crushed into particles with the size less than $2 \mathrm{~mm}$. Then, sludge powder was mixed with binder. After this, about $20 \mathrm{~mL}$ water was added into the mixture to obtain a paste and finally the paste was extruded into cylindrical samples ( $4 \mathrm{~mm}$ diameter and $9 \mathrm{~mm}$ long). The prepared samples were dried for $12 \mathrm{~h}$ at $105^{\circ} \mathrm{C}$. And then the samples were heated up to $300{ }^{\circ} \mathrm{C}^{13}$ with a selected heating rate and held for $1 \mathrm{~h}$ under nitrogen flow 


\begin{tabular}{|c|c|c|c|c|c|c|c|}
\hline \multicolumn{8}{|c|}{$\begin{array}{c}\text { TABLE-1 } \\
\text { ULTIMATE AND PROXIMATE ANALYSIS OF THE RAW MATERIALS }\end{array}$} \\
\hline Material & Moisture (\%) & Volatiles (\%) & Ash (\%) & Fixed carbon $(\%)$ & $\mathrm{C}(\%)$ & $\mathrm{H}(\%)$ & $\mathrm{N}(\%)$ \\
\hline Sludge & 71.2 & 45.7 & 47.45 & 6.85 & 16.82 & 3.26 & 3.12 \\
\hline
\end{tabular}

$(0.6 \mathrm{~L} / \mathrm{min})$ in order to prevent carbon $\operatorname{loss}^{14}$. The temperature was further raised to a predetermined final temperature at the same heating rate and kept for a certain time. After this step, the samples were activated. Last, the samples were cooled naturally in the nitrogen atmosphere.

Dye equilibrium adsorption experiments: Dye, methylene blue, with a chemical formula of $\mathrm{C}_{16} \mathrm{H}_{18} \mathrm{~N}_{3} \mathrm{CINS} \cdot 3 \mathrm{H}_{2} \mathrm{O}$ and molecular weight of $373.90 \mathrm{~g} / \mathrm{mol}$ (Kelong, Co. Ltd., Chengdu, P.R. China) was chosen as the targeted adsorbate in this study.

Equilibrium adsorption studies were conducted in a set of $250 \mathrm{~mL}$ Erlenmeyer flasks containing $0.20 \mathrm{~g}$ adsorbent and $200 \mathrm{~mL}$ dye solutions with various initial concentrations $(50$, 100, 200, 300 and $400 \mathrm{mg} / \mathrm{L})$. The flasks were stirred in an isothermal water-bath shaker at $120 \mathrm{rpm}$ and kept at $26^{\circ} \mathrm{C}$ until the equilibrium was reached. Once methylene blue arrived at equilibrium, $\mathrm{q}_{\mathrm{e}}(\mathrm{mg} / \mathrm{g})$, was calculated by eqn. $1^{15}$ :

$$
\mathrm{q}_{\mathrm{e}}=\frac{\left(\mathrm{C}_{0}-\mathrm{C}_{\mathrm{e}}\right) \mathrm{V}}{\mathrm{W}}
$$

where $\mathrm{C}_{0}$ and $\mathrm{C}_{\mathrm{e}}(\mathrm{mg} / \mathrm{L})$ are the liquid-phase concentrations of dye at initial and equilibrium, respectively and was determined by UV-visible spectrophotometry at a wavelength of $665 \mathrm{~nm}(\mathrm{~L})$ is the volume of the solution and $(\mathrm{g})$ is the mass of adsorbent used.

The obtained adsorption data were the average of three tests. The obtained adsorption data were fitted by different isotherm models. It was found that the experimental data were best fitted by Langmuir equation with $\mathrm{R}^{2}$ values were all over 0.99 , indicating that the methylene blue adsorption of the samples was only affected by surface area. Therefore, the adsorption of methylene blue was calculated by Langmuir equation. Moreover, the adsorption of methylene blue generally happened in pores with a size greater than $1.3 \mathrm{~nm}^{16}$. It is indicated that adsorption of methylene blue is mainly controlled by mesoporous surface area.

Characterization of sample prepared under optimized conditions: The surface area and the porosity of the sewage sludge based granular activated carbon prepared under optimized conditions were characterized by nitrogen adsorption at $77 \mathrm{~K}$ (Micromeritics ASAP 2020M). Scanning electron microscope (SEM) apparatus (FEI Quanta250) was used to study the surface morphology and the porosity of the prepared sewage sludge based granular activated carbon. An FT-IR spectroscope (FTIR, Perkin-Elmer Spectrum GX) with KBr pellet was used to detect the surface functional groups of the sewage sludge based granular activated carbon.

\section{RESULTS AND DISCUSSION}

Optimization of sewage sludge based granular activated carbons preparation: Fig. 1a shows the variation of methylene blue adsorption capacity of the samples prepared at different activation temperatures. It is clear that the methylene blue adsorption increases first and then decreases
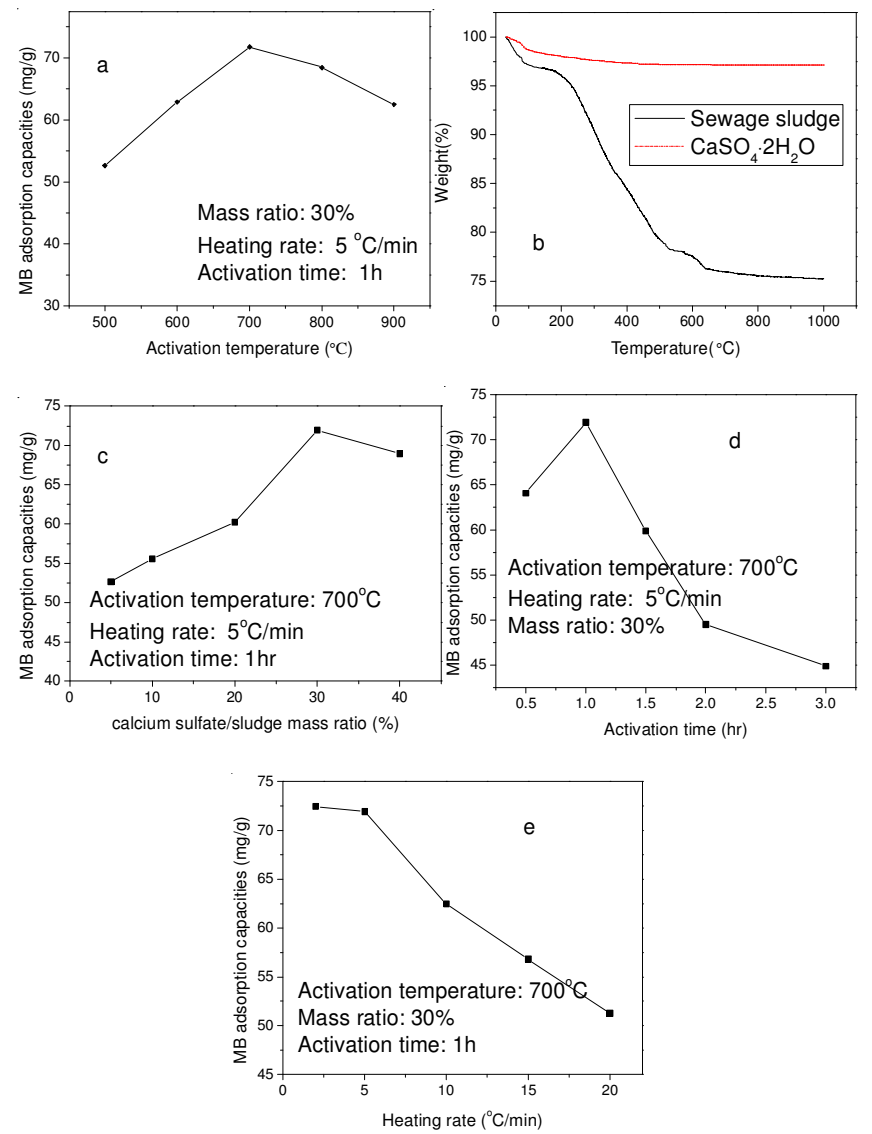

Fig. 1. Effect of preparation conditions on methylene blue adsorption (a, c, d, e) and TGA curves of $\mathrm{CaSO}_{4}$ and sewage sludge (b)

as the temperature rises, which is attributed to the surface area variation of mesopores with activation temperatures. When the temperature is in the range of $500-700{ }^{\circ} \mathrm{C}$, the volatiles of samples are continuously released with increasing activation temperature, which is confirmed by the TGA measurement of sludge (Fig. 1b). And the continuous evaporation of volatiles has resulted in some new pores developed. Moreover, the $\mathrm{C}-\mathrm{CaSO}_{4}$ reaction rate increases with the increase of activation temperature and the carbons on the pore walls are burned-off, which causes pore size widened. Both reactions have enhanced the mesoporous surface area of samples. However, when the temperature further increases from 700 to $900{ }^{\circ} \mathrm{C}$, the mesoporous surface area of samples would decrease. There are two reasons: (1) pore blockage ${ }^{17}$ and pore collapse ${ }^{18}$ could also happen except above two reactions; (2) the excessive carbons on the walls of pores are burned-off by $\mathrm{C}-\mathrm{CaSO}_{4}$ reaction, causing the mesopores developed into macropores. Therefore, the optimal activation temperature should be $700{ }^{\circ} \mathrm{C}$.

Generally, the surface area, pore volume and adsorption capacity of granular activated carbon are reduced with binder dosages ${ }^{19}$. However, the methylene blue adsorption capacities of the products prepared in this work (Fig. 1c) are different with the previous studies. As shown in Fig. 3, the methylene blue adsorption capacities are firstly increased and then 
depressed with calcium sulphate dosages. This indicates that the activation of calcium sulphate could play an important role in the pore development by increasing the mass ratio of calcium sulphate/sludge. As the dosages of the calcium sulphate increase, more micropores are widened, resulting in an increase of mesoporous surface area. However, when the calcium sulphate is excessive, the pore size is further widened, causing the decrease of mesoporous surface area ${ }^{20}$. Correspondingly, the methylene blue adsorption capacities are fluctuant. A similar behaviour of methylene blue adsorption was also reported by Foo and Hameed ${ }^{21}$.

Fig. 1d shows the variation of methylene blue adsorption capacities with activation time. It can be seen that the methylene blue adsorption capacities firstly enhance and then decrease with the increase of activation time. This is due to that the mesoporous surface area of the sample presents the same variation tendency with the increase of carbonization time. During the activation process, the activation reaction of $\mathrm{C}$ $\mathrm{CaSO}_{4}$ becomes more complete and develops more mesopores with activation time prolonging ${ }^{22}$. The increase of mesopores may be attributed to two reasons: on one hand, the previously blocked mesopores are opened by the pore drilling effect of activation reaction and on the other hand, the micropores become mesopores by hole expending effect of activation reaction. However, with the further increase of activation time, mesopores could turn into macropores due to the burning-off of excessive carbons on pore walls.

The effect of heating rates on the methylene blue adsorption capacities is also investigated and shown in Fig. 1e. The methylene blue adsorption capacities values decrease as the heating rate increases from 2 to $20^{\circ} \mathrm{C} / \mathrm{min}$. This is perhaps owing to the less destruction of samples structure caused by high heating rate. When the heating rate is low, the extraction of volatile compounds and the decomposition of cellulose and hemicellulose are sufficient $t^{23}$, leading to an ordered carbon structure. And meantime, more pores are created. The moderate activation reaction with ordered carbon structure, the more suitable formation of mesopores. At high heating rates, samples structure is probably destructed and turned into $\operatorname{ash}^{5,24}$, resulting in the decrease of pores. It can be concluded that the sample prepared with $2^{\circ} \mathrm{C} / \mathrm{min}$ heating rate has the greatest methylene blue adsorption capacity, but we advise that the $5^{\circ} \mathrm{C} / \mathrm{min}$ heating rate is adopted in practice in order to save energy.

Characterization of the sewage sludge based granular activated carbon prepared under optimized conditions: The nitrogen adsorption/desorption isotherm curve of the sewage sludge based granular activated carbon prepared under the optimized conditions at $77 \mathrm{~K}$. According to IUPAC classification, the isotherm suggests a type II adsorption/desorption, in which most porosity of sewage sludge based granular activated carbon is in mesoporous dimensions. The structural parameters obtained from analyzing the isotherm with BET, t-plot and BJH methods are as follows: specific surface area
$14.27 \mathrm{~m}^{2} / \mathrm{g}$, microporous surface area $1.9354 \mathrm{~m}^{2} / \mathrm{g}$ and mesoporous surface area $10.39 \mathrm{~m}^{2} / \mathrm{g}$. The comparison of surface areas shows that the sewage sludge based granular activated carbon produced under optimized conditions has welldeveloped mesopores, which is suitable for methylene blue adsorption $^{16}$.

The surface morphology of sewage sludge based granular activated carbon prepared under optimized conditions was observed by SEM. It is obvious that there are many ablated holes and a few of cracks.

According to the FT-IR spectrum of the sewage sludge based granular activated carbon produced under optimized conditions, it can be clearly seen that the band at $3448.1 \mathrm{~cm}^{-1}$ could be due to $\mathrm{O}-\mathrm{H}$ stretching vibration in alcohols. The bands at 1637.3 and $1420.3 \mathrm{~cm}^{-1}$ are attributed to $\mathrm{C}=\mathrm{O}$ stretching vibration of carbonyl groups and $\mathrm{COOH}$ groups vibration, respectively. While the bands at 1119.7 and $1155 \mathrm{~cm}^{-1}$ are ascribed to $\mathrm{C}-\mathrm{O}$ stretching in alcohol and asymmetric stretching vibration (-C-O-C-ring). The bands around $1020 \mathrm{~cm}^{-1}$ may be assigned to $\mathrm{C}-\mathrm{OH}$ stretching. A broad band in the range of $800-400 \mathrm{~cm}^{-1}$ is due to the bending vibration of $-\mathrm{OH}$ groups, stretching vibration of $\mathrm{C}-\mathrm{O}$ groups, $-\mathrm{NH}_{2}$ group or $\mathrm{C}-\mathrm{H}$ (benzene derivatives) functional group.

Activation mechanism of calcium sulphate: In order to investigate the activation mechanism of calcium sulphate, the elemental analyses of carbon, calcium and sulfur in the sample before and after carbonization and activation were carried out and the results are listed in Table- 2 .

It can be seen that the carbon is almost gone after activation. And meantime, the molar ratio of calcium and sulfur is significantly increased. Moreover, besides the weight loss caused by evaporation of crystallization water, there is no another obvious weight loss according to TGA of calcium sulphate (Fig. 1b). These all indicate that the sulphate is indeed involved in the activation reaction. The activation of sulphate could follow the reactions: $\mathrm{H}_{2} \mathrm{O}$ (organic matter pyrolysis) $\rightarrow$ $\mathrm{H}^{+}+\mathrm{OH}^{-}$and $\left.4 \mathrm{H}^{-}+2 \mathrm{SO}_{4}{ }^{2+}+\mathrm{C} \rightarrow 2 \mathrm{SO}_{2}+\mathrm{CO}_{2}+2 \mathrm{H}_{2} \mathrm{O}\right)$.

This activation process is very similar to that of $\mathrm{H}_{2} \mathrm{SO}_{4}{ }^{25}$. Moreover, the stable $\mathrm{C}-\mathrm{O}$ complexes may be introduced by $\mathrm{H}_{2} \mathrm{SO}_{4}$ activation ${ }^{21}$. The bands at $1119.7 \mathrm{~cm}^{-1}$ and less than $800 \mathrm{~cm}^{-1}$ are ascribed to C-O stretching in alcohol and stretching vibration of $\mathrm{C}-\mathrm{O}$ groups, which also indicating sulphate acts as activator.

In addition, calcium is an active metal and its activity is only lower than potassium among common metals. During the process of preparation of activated carbons, potassium hydroxide ${ }^{15}$, potassium salt ${ }^{26}$ and sodium hydroxide ${ }^{27}$ are usually used as activating agents. So it is concluded that calcium in calcium sulphate may be another activating agent in this study. Besides, the study on the synthesis of nitrogendoped porous graphitic carbons conducted by Yang et al. ${ }^{28}$ confirmed that calcium salt could be used as activating agent.

TABLE-2

ELEMENTAL ANALYSIS OF SSGAC BEFORE AND AFTER CARBONIZATION AND ACTIVATION

\begin{tabular}{ccccc}
\hline Item & $\mathrm{C}(\%)$ & $\mathrm{Ca}(\%)$ & $\mathrm{S}(\%)$ & $\mathrm{Ca}(\mathrm{mol}): \mathrm{S}(\mathrm{mol})$ \\
\hline Before carbonization and activation & 12.92 & 5.37 & 4.29 & $1.00: 1.00$ \\
After carbonization and activation & Trace & 18.45 & 9.72 & $1.52: 1.00$ \\
\hline
\end{tabular}


According to the activation mechanisms of the $\mathrm{H}_{2} \mathrm{SO}_{4}$, $\mathrm{KOH}, \mathrm{K}_{2} \mathrm{CO}_{3}$ and $\mathrm{NaOH}$, activation reactions of calcium sulphate may be as follows:

$$
\begin{gathered}
\mathrm{H}_{2} \mathrm{O} \text { (Organic matter pyrolysis) } \rightarrow \mathrm{H}^{+}+\mathrm{OH}^{-} \\
\mathrm{CaSO}_{4} \rightarrow \mathrm{Ca}^{2+}+\mathrm{SO}_{4}^{2-} \\
4 \mathrm{H}^{+}+2 \mathrm{SO}_{4}^{2+}+\mathrm{C} \rightarrow 2 \mathrm{SO}_{2}+\mathrm{CO}_{2}+2 \mathrm{H}_{2} \mathrm{O} \\
3 \mathrm{Ca}^{2+}+6 \mathrm{OH}^{-}+\mathrm{C} \rightarrow \mathrm{Ca}+3 \mathrm{H}_{2}+2 \mathrm{CaCO}_{3} \\
\mathrm{CaCO}_{3}+\mathrm{C} \rightarrow \mathrm{CaO}+\mathrm{CO}_{2} \\
\mathrm{Ca}+\mathrm{CO}_{2} \rightarrow \mathrm{CaO}+\mathrm{CO} \\
\mathrm{Ca}^{2+}+2 \mathrm{OH}^{-} \rightarrow \mathrm{CaO}+\mathrm{H}_{2} \mathrm{O} \\
\mathrm{H}_{2} \mathrm{O}+\mathrm{C} \rightarrow \mathrm{H}_{2}+\mathrm{CO}
\end{gathered}
$$

\section{Conclusion}

In this study, sewage sludge based granular activated carbons used for removal of methylene blue were prepared using calcium sulphate as binder and activator. The effect of preparation conditions on adsorption of methylene blue was detailedly investigated. The results showed that the sample prepared under the conditions of activation temperature $700{ }^{\circ} \mathrm{C}$, calcium sulphate and sludge mass ratio $30 \%$, activation time $1 \mathrm{~h}$ and heating rate $5{ }^{\circ} \mathrm{C} / \mathrm{min}$ had the greatest methylene blue adsorption $(71.94 \mathrm{mg} / \mathrm{g})$. And then the characterization of the sample prepared under the optimized conditions indicated that it was a typical mesoporous adsorbent and there were many acidic groups and holes caused by ablating on its surfaces. According to the elemental analyses of the sample before and after carbonization and activation as well as literatures, the mechanism and reaction of calcium sulphate activation were proposed. The mechanism of calcium sulphate activation was similar to that of the combination of $\mathrm{H}_{2} \mathrm{SO}_{4}$ and $\mathrm{KOH}$.

\section{ACKNOWLEDGEMENTS}

This work was supported by the Major National Science and Technology Program for Water Pollution Control and Treatment (No. 2012ZX07307-001).

\section{REFERENCES}

1. M.J. Martin, A. Artola, M.D. Balaguer and M. Rigola, Chem. Eng. J., 94, 231 (2003).

2. C.C. Small, Z. Hashisho and A.C. Ulrich, Fuel, 92, 69 (2012).

3. I.A.W. Tan, A.L. Ahmad and B.H. Hameed, J. Hazard. Mater, 154, 337 (2008)

4. G. Alagumuthu and M. Rajan, Chem. Eng. J., 158, 451 (2010).

5. F. Rozada, M. Otero, A. Moran and A. Garcia, J. Hazard. Mater. B, 124, 181 (2005).

6. X.J. Wang, X. Liang, Y. Wang, X. Wang, M. Liu, D.Q. Yin, S.Q. Xia, J.F. Zhao and Y.L. Zhang, Desalination, 278, 231 (2011).

7. S. Rio, C. Faur-Brasquet, L.L. Coq, P. Courcoux and P.L. Cloirec, Chemosphere, 58, 423 (2005).

8. A. Méndez, G. Gascó, M.M.A. Freitas, G. Siebielec, T. Stuczynski and J.L. Figueiredo, Chem. Eng. J., 108, 169 (2005).

9. M. Otero, F. Rozada, A. Morán, L.F. Calvo and A.I. García, Desalination, 239, 46 (2009).

10. F.S. Zhang, J.O. Nriagu and H. Itoh, Water Res., 39, 389 (2005).

11. X.N. Wang, N.W. Zhu and B.K. Yin, J. Hazard. Mater., 153, 22 (2008).

12. X.D. Fan and X.K. Zhang, Mater. Lett., 62, 1704 (2008).

13. W.H. Li, Q.Y. Yue, B.Y. Gao, Z.H. Ma, Y.J. Li and H.X. Zhao, Chem. Eng. J., 171, 320 (2011).

14. A.C. Lua and T. Yang, J. Colloid Interf. Sci., 274, 594 (2004).

15. K.Y. Foo and B.H. Hameed, Desalination, 275, 302 (2011).

16. A.A. El-Hendawy, S.E. Samra and B.S. Girgis, Colloids Surf. A Physicochem. Eng. Asp., 180, 209 (2001).

17. W.H. Li, Q.Y. Yue, B.Y. Gao, X.J. Wang, Y.F. Qi, Y.Q. Zhao and Y.J. Li, Desalination, 278, 179 (2011).

18. D. Kalderis, S. Bethanis, P. Paraskeva and E. Diamadopoulos, Bioresour. Technol., 99, 6809 (2008).

19. A.P. Carvalho, A.S. Mestre, J. Pires, M.L. Pinto and M.E. Rosa, Micropor. Mesopor. Mater., 93, 226 (2006).

20. LiangGaoLiTangLiuYu. Q. Liang, L.Z. Gao, Q. Li, S.H. Tang, B.C. Liu and Z.L. Yu, Carbon, 39, 897 (2001).

21. K.Y. Foo and B.H. Hameed, Chem. Eng. J., 184, 57 (2012).

22. J.F. Sun, X.Q. Wang, C.S. Wang and Q.R. Wang, J. Appl. Polym. Sci., 99, 2565 (2006).

23. C. Bouchelta, M.S. Medjram, M. Zoubida, F.A. Chekkat, N. Ramdane and J.P. Bellat, J. Anal. Appl. Pyrolysis, 94, 215 (2012).

24. P. Ariyadejwanich, W. Tanthapanichakoon, K. Nakagawa, S.R. Mukai and H. Tamon, Carbon, 41, 157 (2003).

25. M.T. Izquierdo, B. Rubio, C. Mayoral and J.M. Andres, Appl. Catal. $B, 33,315$ (2001).

26. D. Adinata, W.M.A. Wan Daud and M.K. Aroua, Bioresour. Technol., 98, 145 (2007).

27. A.L. Cazetta, A.M.M. Vargas, E.M. Nogami, M.H. Kunita, M.R. Guilherme, A.C. Martins, T.L. Silva, J.C.G. Moraes and V.C. Almeida, Chem. Eng. J., 174, 117 (2011).

28. G.W. Yang, H.Y. Han, T.T. Li and C.Y. Du, Carbon, 50, 3753 (2012). 